\title{
Dilated cardiomyopathy associated with chronic overuse of an adrenaline inhaler
}

\author{
M J Stewart, D M Fraser, N Boon
}

\begin{abstract}
Endogenous catecholamines in excess are known to cause dilated cardiomyopathy. A patient presented with dilated cardiomyopathy after many years of overusing an adrenaline inhaler.

Pathological features and a considerable improvement in myocardial function after withdrawal implicated the exogenous catecholamine excess in the pathogenesis of the cardiomyopathy.
\end{abstract}

(Br Heart J 1992;68:221-2)

Catecholamine induced cardiomyopathy is a recognised complication of phaeochromocytoma. ${ }^{1}$ We report a case in which excessive self medication with an adrenaline containing inhaler used for asthma resulted in a similar clinical condition.

\section{Case report}

A 44 year old seaman presented with a short history of increasing breathlessness and wheeze. He had had asthma since childhood, smoked 30 cigarettes a day, and drank less than 20 units of alcohol per week.

On admission he was taking one tablet of Franol (11 mg ephedrine hydrochloride, $8 \mathrm{mg}$ phenobarbitone, $120 \mathrm{mg}$ theophylline) three times daily and a Brovon inhalant spray $(0.5 \%$ adrenaline, $0.14 \%$ atropine methonitrate, $0.88 \%$ papaverine hydrochloride) taken as required. Although the maximum recommended dose of the Brovon inhaler is three puffs a day, our patient was in the habit of using the inhaler up to 40 times a day and had done so for 20 years. He had resisted attempts by his general practitioner to convert him to a salbutamol inhaler, which he found lacked effect.

On examination he was obese and tachypnoeic at rest with tachycardia of 120 beats per min. The chest was hyperexpanded with intercostal muscle indrawing and widespread inspiratory and expiratory wheeze. The peak expiratory flow rate was $130 \mathrm{l} / \mathrm{min}$. Arterial blood gases measured while he was breathing air were $\mathrm{pH} 7 \cdot 34, \mathrm{Po}_{2} 8 \cdot 8 \mathrm{kPa}, \mathrm{Pco}_{2} 7 \cdot 0 \mathrm{kPa}$. A chest $x$ ray film showed cardiomegaly (cardiothoracic ratio (CTR) 205/330) with generalised increase in lung markings; an electrocardiogram showed $\mathbf{P}$ pulmonale, right axis deviation, and clockwise rotation.

The patient was admitted to hospital. Treatment with the Brovon inhaler and Franol were stopped and he was treated with nebulised salbutamol, ipratropium bromide and oral theophylline. As a result of these measures the peak expiratory flow rate rose to $200 \mathrm{l} / \mathrm{min}$ but he remained very breathless. Examination five days after admission showed signs of congestive cardiac failure. The jugular venous pressure was elevated by $8 \mathrm{~cm}$, there was moderate ankle oedema, and a third heart sound. A chest $x$ ray now showed considerable pulmonary venous congestion.

The clinical features of congestive cardiac failure improved after treatment with diuretics and captopril. Cross sectional echocardiography showed dilated right and left ventricles with poor systolic function and an isotope ventriculogram showed a left ventricular ejection fraction of $7 \%$. Serum ferritin and thyroid function tests were normal. Concentrations of C3 and C4 were normal, double stranded DNA titre was $0.8 \mathrm{mg} /$ litre, and serological tests for viruses were negative.

Cardiac catheterisation showed a grossly dilated left ventricle with global impairment of systolic function. The ventricular end diastolic pressure was $30 \mathrm{~mm} \mathrm{Hg}$ and there was moderate pulmonary hypertension with a pulmonary artery pressure of $60 / 40$ (mean 45 ) $\mathrm{mm} \mathrm{Hg}$.

Light microscopy of three right ventricular biopsy specimens obtained by the same procedure showed variation in size of myocardial cells with hypertrophy, nucleomegaly, and focal vacuolation of the fibres. There was no necrosis or inflammatory infiltrate. Electron microscopy studies confirmed the presence of contraction bands and showed focal disruption of myofibrillar architecture with notable lipochrome deposition.

The patient continued to improve with oral diuretics and an angiotensin converting enzyme inhibitor and chest $x$ ray film three months later confirmed noticeable improvement in the congestive changes (CTR $180 / 330$ ) (figure). An isotope ventriculogram six months after use of the Brovon inhaler was stopped showed that the left ventricular ejection fraction had risen to $17 \%$.

\section{Discussion}

Myocarditis and myocardial impairment have been reported after exposure to high concentration of endogenous ${ }^{23}$ and exogenous ${ }^{4}$ catecholamines. In laboratory animals the histological picture is similar whatever the catecholamine or the route of administration, and the severity and extent of the damage is 
Chest $x$ ray films five days (A) and three months (B) after presentation. Pulmonary congestion improved and the cardiothoracic ratio fell from $205 / 330(62 \%)$ to $180 / 330(54 \%)$.
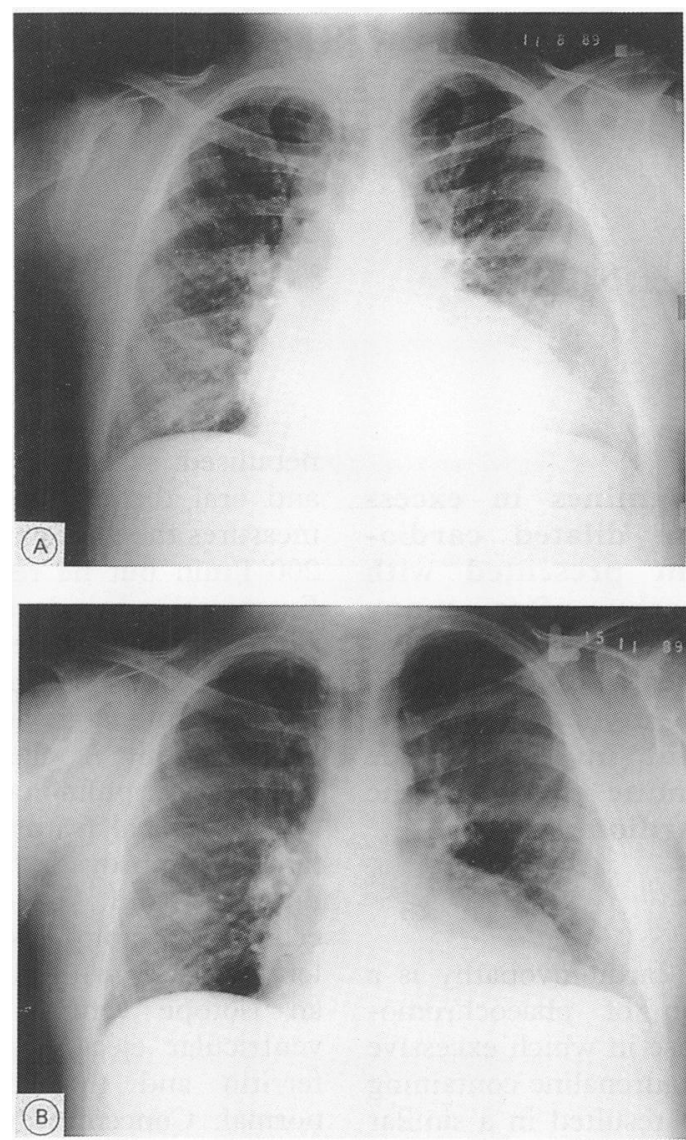

determined by the dose and the duration of exposure. ${ }^{5}$

Myocardial toxicity was implicated in the rise in asthma mortality associated with the use and misuse of aerosols containing sympathomimetic bronchodilators, ${ }^{6}$ and transient myocardial ischaemia and myocardial infarction have also been described in asthmatic patients who use isoprenaline inhalers at therapeutic doses.?

Catecholamine mediated myocardial toxicity was implicated in sudden death in glue sniffers who misused substances that sensitised the heart to endogenous catecholamines. ${ }^{8}$ Dilatated cardiomyopathy associated with solvent abuse has also been reported..$^{9}$

The dilated cardiomyopathy associated with phaeochromocytoma is thought to be due to chronic exposure to high concentrations of catecholamines. The pathogenesis is not clear but probably involves ischaemia, due to catecholamine induced vasoconstriction and reduced coronary blood flow, ${ }^{11}$ and cell membrane damage caused by the toxic effects of metabolites and cytotoxic free radicals produced by oxidation of catecholamines. ${ }^{12}$

We believe that the chronic overuse of an adrenaline inhaler caused a similar form of cardiomyopathy in our patient. The histological lesions were not specific but they accorded with those found in dilated cardiomyopathy. Postmortem studies of patients dying of phaeochromocytoma showed active myocarditis in some and myocardial fibrosis in others. $^{2}$ The limitation of sampling in biopsy procedures precludes exclusion of an inflammatory component; but in studies of myocardial biopsy specimens in dilated cardiomyopathy the frequency of myocarditis seldom exceeded $5 \% .{ }^{13}$ Moreover, if catecholamine toxicity is mediated through membrane damage an inflammatory component may be an inconstant feature. Lipochrome, seen in electron microscopy, is a common accompaniment to cell ageing, and was notable in our patient. This may relate to increased membrane turnover, accelerated by free radical damage to the membranes.

The reversibility of acute myocardial impairment after a phaeochromocytoma crisis ${ }^{3}$ and the lessening of cardiac failure in catecholamine cardiomyopathy after successful surgical removal of phaeochromocytoma have been emphasised, ${ }^{14}{ }^{15}$ so the rise in ejection fraction (from 7 to $17 \%$ ) would also tend to support our contention. As far as we know this is the first description of a dilated cardiomyopathy caused by exogenous catecholamines.

The prescription of inhalers containing adrenaline has declined dramatically since the concern over their role in asthma deaths in the 1960 s and Brovon inhalant solution was withdrawn in October 1989. Inhalant solutions containing adrenaline are, however, still marketed and the dangers of overusing these products must be recognised.

We thank Dr $\mathrm{K}$ McLaren for helpful advice regarding the significance of the histological lesions and Dr T M J Griffin for analysing the nuclear ventriculograms and providing the illustrations.

Sardesai SH, Mourant AJ, Sivathandon Y, Farrow R, Gibbons DO. Phaeochromocytoma and catecholamin induced cardiomyopathy presenting as heart failure. Br Heart J 1990;63:234-7.

2 van Vliet PD, Burdell HB, Titus TL. Focal myocarditis associated with phaeochromocytoma. $N E n g l J M e d$ 1966;274:1102-8.

3 Shaw TR, Rafferty P, Tait GW. Transient shock and myocardial impairment caused by phaeochromocytom crisis. Br Heart $J$ 1987;57:194-8.

4 Szakacs JE, Cannon A. L-norepinephrine myocarditis. Am Clin Pathol 1958;30:425-34.

5 Haft J. Cardiovascular injury induced by sympathetic catecholamines. Prog Cardiovasc Dis 1974;XVII:73-86.

6 Inman WH, Adelstein AM. Rise and fall of asthma mortality in England and Wales in relation to use of pressurised aerosols. Lancet 1969;ii:279-84.

7 Winsor T, Berger HJ. Isoproterenol toxicity. Am Heart $J$ $1975 ; 89: 814-7$

8 Bass M. Sudden sniffing death. JAMA 1970;212:2075-9.

9 McLeod AA, Marjot R, Monoghan MJ, Hugh-Jones $P$ Jackson G. Chronic cardiac toxicity after inhalation of 1,1,1,-trichloroethane. Br Med J 1987;294:727-9.

10 Wiseman MN, Banim S. Glue sniffer's heart. Br Med 1987;294:739.

11 Simons M, Downing SE. Coronary vasoconstriction and catecholamine cardiomyopathy. Am Heart J 1985;109: 297-304.

12 Singal PK, Kapur N, Dhillon KS, Beamish RE, Dhalla NS Role of free radicals in catecholamine induced cardiomyopathy. Can J Physiol Pharmacol 1982;60: 1390-7.

13 Chow LC, Dittrich HC, Shabetai R. Endomyocardial biopsy in patients with unexplained congestive heart failure. Ann Intern Med 1988;109:535-9.

14 Imperato-McGinley J, Gautier T, Ehlers K, Zallo MA, Goldstein DS, Vaughan ED. Reversibility of catecholamine induced dilated cardiomyopathy in a child with a phaeochromocytoma. N Engl J Med 1987;316:793-7.

15 Lam JB, Shub C, Sheps SG. Reversible dilatation of hypertrophied left ventricle in phaeochromocytoma: serial two-dimensional echocardiographic observations. $\mathrm{Am}$ two-diment J 1985;109:613-5. 